\title{
Factors Associated with the Risk of Adenoma Recurrence in Distal and Proximal Colon
}

\author{
Adeyinka O. Laiyemo $^{\mathrm{a}, \mathrm{b}}$ Chyke Doubeni ${ }^{\mathrm{g}}$ Paul F. Pinsky ${ }^{c}$ V. Paul Doria-Rose ${ }^{\mathrm{d}}$ \\ Pamela M. Marcus ${ }^{d}$ Robert E. Schoen ${ }^{\text {h }}$ Elaine Lanza ${ }^{\text {e }}$ Amanda J. Cross $^{f}$ \\ aDivision of Gastroenterology, Department of Medicine, Howard University College of Medicine, \\ Washington, D.C., b Biometry Research Group, Division of Cancer Prevention, 'Early Detection Research Group, \\ Division of Cancer Prevention, National Cancer Institute, ${ }^{\mathrm{d} H e a l t h}$ Services and Economics Branch, Division of Cancer

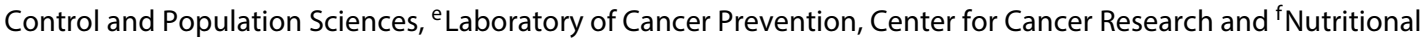 \\ Epidemiology Branch, Division of Cancer Epidemiology and Genetics, National Cancer Institute, National Institutes \\ of Health, Bethesda, Md., 9 Department of Family Medicine, University of Massachusetts, Worcester, Mass., and \\ h Department of Medicine and Epidemiology, University of Pittsburgh, Pittsburgh, Pa., USA
}

\section{Key Words}

Adenomatous polyps - Colonoscopy - Advanced adenoma .

Proximal adenoma $\cdot$ Distal adenoma

\begin{abstract}
Background/Aims: Colonoscopy may be less effective in preventing cancer in the proximal colon. We evaluated whether risk factors for adenoma recurrence exhibit differential effect on adenoma recurrence by colon subsite. Methods: We examined the association of age, sex, body mass index, smoking status and use of nonsteroidal anti-inflammatory drugs (NSAIDs) on proximal and distal adenoma recurrence among 1,864 participants in the Polyp Prevention Trial. We used multinomial logistic regression models to calculate the relative risk ratios (RRR) and $95 \% \mathrm{Cl}$. Results: 733 (39.3\%) participants had adenoma recurrence (228 distal only, 369 proximal only and 136 synchronous proximal and distal adenoma). When compared to participants without adenoma recurrence, no factor was associated with an increased risk of distal only adenoma recurrence. Age 65-69
\end{abstract}

\section{KARGER}

E-Mail karger@karger.com

www.karger.com/dig years $(\mathrm{RRR}=1.47,95 \% \mathrm{Cl} 1.00-2.16)$, age $\geq 70$ years $(\mathrm{RRR}=$ $2.24,95 \% \mathrm{Cl} 1.57-3.20)$, and male sex (RRR $=1.73,95 \% \mathrm{Cl}$ 1.32-2.27) were positively associated with proximal only adenoma recurrence. NSAIDs use was associated with a reduced risk of adenoma recurrence by similar magnitude in distal (RRR $=0.78,95 \% \mathrm{Cl} 0.58-1.07$ ) and proximal colon ( $R R R=0.77,95 \% \mathrm{Cl} 0.60-1.00)$. Conclusions: We did not find any modifiable risk factor that differentially increases proximal as compared to distal adenoma recurrence to be clinically useful for targeted intervention.

Copyright $\odot 2013$ S. Karger AG, Basel

\section{Introduction}

Use of colonoscopy as the primary means of colorectal cancer screening has increased [1,2]. Emerging data, however, suggest that colonoscopy may not be as effective in reducing colon cancer incidence and mortality in the proximal when compared with distal colon [3-7]. Although these studies were not randomized trials of
C 2013 S. Karger AG, Basel

0012-2823/13/0873-0141\$38.00/0
Adeyinka O. Laiyemo, MD, MPH

Division of Gastroenterology, Department of Medicine Howard University College of Medicine 2041 Georgia Avenue, NW, Washington DC 20060 (USA) E-Mail adeyinka.laiyemo@ howard.edu 
screening colonoscopy, the reported differences in the effectiveness of colonoscopy in proximal versus distal colon are compelling.

Explanations of why endoscopic effectiveness may be reduced in the proximal colon include that colonoscopy visualization may be worse in the proximal colon due to poor bowel preparation, that there is less adequate examination by endoscopists in the proximal colon, and that there is less adequate detection of flat and depressed lesions in the proximal colon [8]. However, it is also possible that the biology of colon cancer differs by tumor location. Evidence from laboratory and genetic studies suggests that proximal and distal colon cancers have distinct gene-specific methylation profiles and molecular characteristics $[9,10]$.

It is unknown whether risk factors associated with adenoma recurrence also exhibit proximal versus distal colon differences in their associations. Identification of factors that differentially increase the risk of proximal as compared to distal adenoma recurrence can potentially guide a clinically useful risk stratification scheme. In this secondary analysis of the comprehensive information on adenoma location from the Polyp Prevention Trial (PPT), we examined whether demographic and lifestyle factors are differentially associated with proximal and distal adenoma recurrence.

\section{Methods}

\section{Study Population}

The details of the rationale, design, and results of the PPT have been described in previous publications [11-13]. In brief, the PPT was a 4-year multicenter, randomized, controlled trial designed to assess the effect of a low-fat, high-fiber diet on the risk of recurrence of adenomatous polyps. The study involved 2,079 participants who were at least 35 years of age and had one or more histologically confirmed adenomatous polyp removed within 6 months before randomization. The participants had no previous history of surgical resection of adenomatous polyps, bowel resection, colorectal carcinoma, polyposis syndrome, or inflammatory bowel disease. The clinical trial was approved by the Institutional Review Boards of the National Cancer Institute and each of the eight participating clinical centers. All participants gave written informed consent. A total of 1,905 (91.6\%) participants completed the trial and underwent colonoscopy four years after randomization. The trial took place from 1991 to 1998. The dietary intervention did not affect adenoma recurrence [13]. For the present study, our analytic cohort included 1,864 participants for whom we had complete information on the location of their adenoma.

\section{Exposure Assessment}

At baseline, information on the participant's demographic characteristics, health-related lifestyle, and medication use was obtained through direct interview. For this study, we examined age, sex, BMI, smoking status, and use of nonsteroidal anti-inflammatory drugs (NSAIDs) at least once a month.

\section{Outcome Assessment}

The participants underwent a clearing colonoscopy approximately 1 year after randomization (T1) to remove any missed lesion at qualifying colonoscopy (T0). They were followed for approximately 4 years after randomization, and had follow-up colonoscopy at the end of the trial (T4). Adenomas found at the T4 colonoscopy were the primary outcome. The colonoscopy reports provided information on size, number, and location of polyps. The histology and degree of atypia were confirmed by two trial pathologists. The location of adenomas removed from the rectum to the splenic flexure was defined as distal, while proximal location included the transverse colon to the cecum. We defined an advanced adenoma as adenoma with size $\geq 1 \mathrm{~cm}$ in diameter, or villous histology or high grade dysplasia.

\section{Statistical Analyses}

We used multinomial logistic regression analyses to evaluate the association of baseline characteristics and lifestyle factors with subsequent adenoma recurrence at the end of the trial as our primary analysis. This was to determine the specific risk estimates associated with the colon subsites. We classified adenoma recurrence into 4 mutually exclusive groups according to findings at the end of trial colonoscopy (T4): those without any adenoma recurrence (comparison group); those with distal only; those with proximal only; and those with synchronous (both) distal and proximal adenoma recurrence.

We classified advanced adenoma outcome into 3 mutually exclusive groups: those without any adenoma recurrence (comparison group), those with only distal advanced adenoma recurrence, and those with any proximal advanced adenoma recurrence (this includes those with proximal advanced adenomas only and those with both distal and proximal advanced adenoma recurrence, because few participants had synchronous advanced adenomas in the distal and proximal colon, $\mathrm{n}=12$ ). We conducted a sensitivity analysis in which we added the recurrent synchronous distal and proximal advanced adenomas $(n=12)$ to the distal only advanced adenoma group and found similar results (data not shown).

We have previously reported that patients with proximal adenoma had increased risk of advanced adenoma recurrence [14] and that proximal adenoma at baseline was associated with proximal adenoma at recurrence [15]. Therefore, we included the baseline location of adenoma in all the multivariable models. Although, the colonoscopy performed one year after randomization (T1) was regarded as a clearing colonoscopy to remove potentially missed lesions, we repeated our analysis and added adenomas found at T1 to the end-of-trial colonoscopic findings in a sensitivity analysis.

In a comparative analysis, we also used Poisson regression models to compare the risk factors associated with proximal adenoma and advanced adenoma recurrence and used distal adenoma and advanced adenoma recurrence as the comparison group. We used Stata ${ }^{\circledR}$ statistical software version 11.2 (College Station, Tex., USA) for all analyses. All reported p values correspond to twosided tests. 


\section{Results}

\section{Baseline Characteristics}

Table 1 shows the baseline characteristics of the study participants. The mean age was 61.1 years, $64.3 \%$ male, $73.5 \%$ were overweight or obese and $61 \%$ had a history of smoking.

\section{Adenoma Recurrence by Location}

At follow-up colonoscopy, 1,131 (60.7\%) participants had no recurrence while 733 (39.3\%) had adenoma recurrence. Of these, 228 (31.1\%) participants had distal only, $369(50.3 \%)$ had proximal only and $136(18.6 \%)$ had synchronous distal and proximal adenoma recurrence (table 2). When compared to participants without adenoma recurrence, no factor was a significant independent risk factor for distal only adenoma recurrence. However, we noted that when compared to participants who were younger than 55 years, those age 65-69 years (relative risk ratio $(R R R)=1.47,95 \%$ CI $1.00-2.16$ ), and age $\geq 70$ years $(\mathrm{RRR}=2.24,95 \%$ CI 1.57-3.20) were positively associated with proximal only recurrence, as well as male sex $(\mathrm{RRR}=1.73,95 \%$ CI 1.32-2.27). The use of NSAIDs had borderline reduced association $(\mathrm{RRR}=0.77,95 \% \mathrm{CI}$ $0.60-1.00)$.

We also observed statistically increased risk of synchronous distal and proximal adenoma recurrence in association with advancing age, male sex and obesity (BMI 230) (table 2). In contrast, NSAIDs use was associated with a borderline reduction in distal only $(\mathrm{RRR}=0.78$, 95\% CI 0.58-1.07), proximal only (RRR $=0.77,95 \%$ CI $0.60-1.00)$ and synchronous distal and proximal $(\mathrm{RRR}=$ $0.76,95 \%$ CI 0.51-1.12) adenoma recurrence.

\section{Advanced Adenoma Recurrence by Location}

A total of 119 participants had advanced adenoma recurrence (47 distal only, 60 proximal only and 12 synchronous proximal and distal). No factor was associated with an increased risk of distal only advanced adenoma recurrence whereas advancing age showed a trend towards increased risk of a proximal advanced adenoma, which became statistically significant for participants who were 60 years and older (table 3). The risk of advanced adenoma recurrence was reduced by $>50 \%$ in both colon subsites by the use of NSAIDs.

When we restricted our analysis to the subset of patients with distal only and proximal only adenoma and advanced adenoma recurrence, only male sex was associated with an increased risk of proximal only adenoma recurrence when compared to distal only adenoma recur-
Table 1. Baseline characteristics of participants $(n=1,864)$

\begin{tabular}{lr}
\hline Characteristics & $\mathrm{n}(\%)$ \\
\hline $\begin{array}{l}\text { Mean age }( \pm \text { SD), years } \\
\text { Age categories }\end{array}$ & $61.1 \pm 9.9$ \\
$\quad<55$ years & $480(25.8)$ \\
$\quad 55-59$ years & $286(15.3)$ \\
$\quad 60-64$ years & $338(18.1)$ \\
$\quad 65-69$ years & $338(18.1)$ \\
$\geq 70$ years & $422(22.6)$ \\
Sex & \\
$\quad$ Male & $1,199(64.3)$ \\
Female & $665(35.7)$ \\
BMI & \\
$\quad<25$ & $494(26.5)$ \\
$\quad 25-29$ & $876(47.0)$ \\
$\quad \geq 30$ & $494(26.5)$ \\
Smoking status & $727(39.0)$ \\
$\quad$ Never & $891(47.8)$ \\
Former & $246(13.2)$ \\
Current & $628(33.7)$ \\
Use of NSAIDs at least once/month & \\
Adenoma location at baseline & $1,030(55.3)$ \\
$\quad$ Distal only & $503(27.0)$ \\
Proximal only & $331(17.8)$ \\
Synchronous proximal and distal & \\
&
\end{tabular}

rence $(R R=1.18,95 \%$ CI 1.02-1.38) and advancing age was associated with an increased risk of proximal advanced adenoma recurrence (table 4).

\section{Sensitivity Analysis}

When we added the adenoma removed at colonoscopy performed 1 year after randomization (T1) to the end-oftrial findings (T4), the results were similar except that we observed that male sex became associated with a statistically significant risk of distal adenoma recurrence (RRR $=1.43,95 \%$ CI 1.07-1.92) and distal advanced adenoma recurrence $(\mathrm{RRR}=1.76,95 \%$ CI 1.04-3.00). The risk of synchronous distal and proximal adenoma recurrence also became significant for BMI 25-29 (RRR = 1.48, 95\% CI 1.03-2.13) and current cigarette smoking $(R R R=1.76$, 95\% CI 1.16-2.68).

\section{Discussion}

Although three randomized control trials of screening colonoscopy are currently underway (http://www.clinicaltrials.gov; identifiers NCT00906997, NCT01239082, and NCT00883792), the results are not expected until at 
Table 2. Factors associated with adenoma recurrence by location

\begin{tabular}{|c|c|c|c|c|c|c|c|}
\hline \multirow[t]{2}{*}{ Characteristics } & \multirow{2}{*}{$\begin{array}{l}\text { No recurrence } \\
(\mathrm{n}=1,131) \\
\mathrm{n}(\%)\end{array}$} & \multicolumn{2}{|c|}{$\begin{array}{l}\text { Distal recurrence only } \\
(\mathrm{n}=228)\end{array}$} & \multicolumn{2}{|c|}{$\begin{array}{l}\text { Proximal recurrence only } \\
(\mathrm{n}=369)\end{array}$} & \multicolumn{2}{|c|}{$\begin{array}{l}\text { Synchronous distal and proximal } \\
\text { recurrence }(\mathrm{n}=136)\end{array}$} \\
\hline & & n (\%) & RRR (95\% CI) & $\mathrm{n}(\%)$ & RRR (95\% CI) & n (\%) & RRR (95\% CI) \\
\hline \multicolumn{8}{|l|}{ Age categories } \\
\hline$<55$ years & $326(28.8)$ & $63(27.6)$ & 1.0 (reference) & $70(19.0)$ & 1.0 (reference) & $21(15.4)$ & 1.0 (reference) \\
\hline 55-59 years & $188(16.6)$ & $28(12.3)$ & $0.76(0.47-1.23)$ & $57(15.5)$ & $1.34(0.90-1.99)$ & $13(9.6)$ & $1.05(0.51-2.18)$ \\
\hline$\geq 70$ years & $212(18.7)$ & $53(23.3)$ & $1.38(0.91-2.09)$ & $109(29.5)$ & $2.24(1.57-3.20)$ & $48(35.3)$ & $3.56(2.03-6.23)$ \\
\hline \multicolumn{8}{|l|}{ Sex } \\
\hline Female & $458(40.5)$ & $79(34.7)$ & 1.0 (reference) & $97(26.3)$ & 1.0 (reference) & $31(22.8)$ & 1.0 (reference) \\
\hline Male & $673(59.5)$ & $149(65.4)$ & $1.24(0.91-1.69)$ & $272(73.7)$ & $1.73(1.32-2.27)$ & $105(77.2)$ & $2.01(1.30-3.11)$ \\
\hline \multicolumn{8}{|l|}{ BMI } \\
\hline$<25$ & $324(28.7)$ & $57(25.0)$ & 1.0 (reference) & $87(23.6)$ & 1.0 (reference) & $26(19.1)$ & 1.0 (reference) \\
\hline \multicolumn{8}{|l|}{ Smoking status } \\
\hline Former & $530(46.9)$ & $105(46.1)$ & $0.94(0.68-1.29)$ & $193(52.3)$ & $1.14(0.84-1.54)$ & $63(46.3)$ & $0.88(0.58-1.32)$ \\
\hline Current & $147(13.0)$ & $34(14.9)$ & $1.17(0.75-1.82)$ & $41(11.1)$ & $1.12(0.80-1.59)$ & $24(17.7)$ & $1.73(0.99-3.00)$ \\
\hline Use of NSAIDs* & $399(35.3)$ & $71(31.1)$ & $0.78(0.58-1.07)$ & $114(30.9)$ & $0.77(0.60-1.00)$ & $44(32.4)$ & $0.76(0.51-1.12)$ \\
\hline
\end{tabular}

Table 3. Factors associated with advanced adenoma recurrence by location

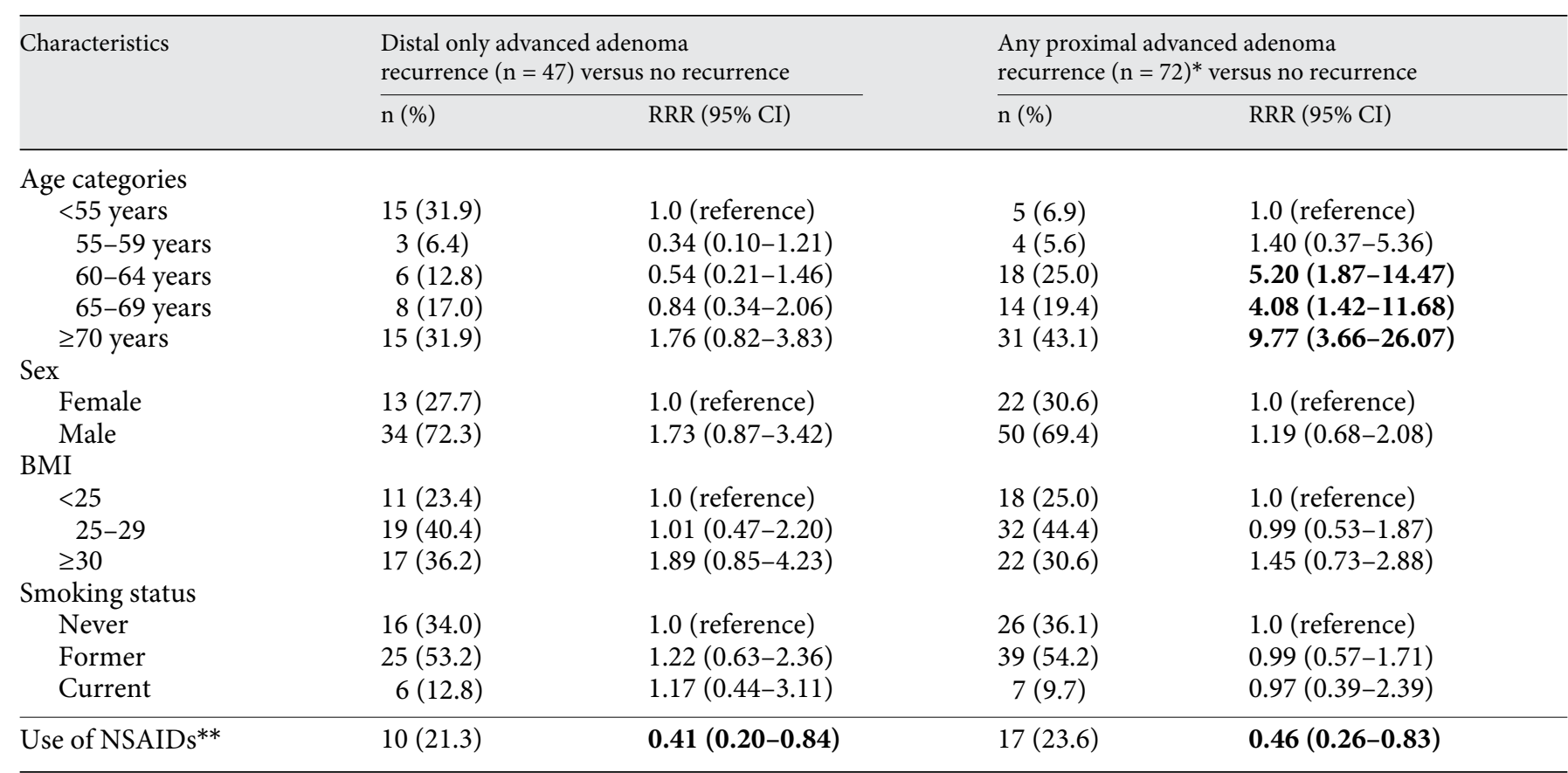

* The combination of proximal advanced adenoma only $(n=60)$ and synchronous proximal and distal advanced adenoma $(n=12)$. ** At least once/month use of NSAIDs: yes versus no. 
Table 4. Comparison of proximal only versus distal only adenoma and advanced adenoma recurrence

\begin{tabular}{|c|c|c|}
\hline Characteristics & $\begin{array}{l}\text { Proximal only }(\mathrm{n}=369) \\
\text { versus distal only }(\mathrm{n}=228) \\
\text { adenoma recurrence } \mathrm{RR} \\
(95 \% \mathrm{CI})\end{array}$ & $\begin{array}{l}\text { Proximal only }(\mathrm{n}=60) \\
\text { versus distal only }(\mathrm{n}=47) \\
\text { advanced adenoma } \\
\text { recurrence RR }(95 \% \mathrm{CI})\end{array}$ \\
\hline \multicolumn{3}{|l|}{ Age categories } \\
\hline$<55$ years & 1.0 (reference) & 1.0 (reference) \\
\hline $55-59$ years & $1.25(1.00-1.55)$ & $3.07(1.18-8.00)$ \\
\hline 60-64 years & $1.03(0.82-1.29)$ & $3.15(1.33-7.49)$ \\
\hline 65-69 years & $1.19(0.96-1.47)$ & $2.68(1.09-6.60)$ \\
\hline$\geq 70$ years & $1.20(0.99-1.46)$ & $3.07(1.30-7.24)$ \\
\hline \multicolumn{3}{|l|}{ Sex } \\
\hline Female & 1.0 (reference) & 1.0 (reference) \\
\hline Male & $1.18(1.02-1.38)$ & $0.87(0.62-1.23)$ \\
\hline \multicolumn{3}{|l|}{ BMI } \\
\hline$<25$ & 1.0 (reference) & 1.0 (reference) \\
\hline $25-29$ & $0.96(0.84-1.16)$ & $0.88(0.58-1.35)$ \\
\hline$\geq 30$ & $0.91(0.75-1.09)$ & $0.84(0.55-1.28)$ \\
\hline \multicolumn{3}{|l|}{ Smoking status } \\
\hline Never & 1.0 (reference) & 1.0 (reference) \\
\hline Former & $1.05(0.91-1.20)$ & $0.81(0.60-1.09)$ \\
\hline Current & $0.94(0.75-1.18)$ & $0.99(0.51-1.89)$ \\
\hline Use of NSAIDs* & $1.02(0.89-1.17)$ & $0.96(0.55-1.28)$ \\
\hline
\end{tabular}

least 2021, 2025 and 2026, respectively. Meanwhile, recent population-based reports of lower efficacy of colonoscopy in reducing colon cancer incidence and mortality in proximal versus distal colon [3-6] make it important to investigate factors associated with this findings so that targeted interventions can be developed and implemented. Therefore, we evaluated whether known risk factors for adenoma recurrence increase proximal versus distal adenoma recurrence. Only male sex and advancing age were associated with proximal only adenoma recurrence and these are nonmodifiable risk factors.

Our findings corroborate the suggestion that cancer prevention in the proximal colon may be quite challenging. The risk factors that have been associated with adenoma recurrence may not be useful for identifying those at a higher risk for proximal colon cancer for targeted intervention. This makes it imperative to perform high quality screening and surveillance colonoscopy. Future studies should also evaluate other approaches including the use of biomarkers.

Only obesity has been studied previously with respect to distal and proximal adenoma recurrence. Jacobs et al. [16] reported an increased odds of proximal adenoma recurrence $(\mathrm{OR}=1.34,95 \% \mathrm{CI} 1.15-1.57)$ for obese pa- tients ( $\mathrm{BMI} \geq 30$ ), but there was no association with distal adenoma recurrence $(\mathrm{OR}=1.02,95 \% \mathrm{CI} 0.81-1.27)$. Other studies have evaluated risk factors for proximal and distal colon cancer. Using the Illinois tumor registry, Nelson et al. [17] reported that age and male sex were independently associated with both proximal and distal colon cancer risk. They also reported that males had higher odds of both proximal and distal colon cancer. In another study, Gonzalez et al. [18] analyzed the incident cases of colon cancer from Florida's statewide cancer registry and reported that increasing age, female sex and the presence of comorbid illnesses were associated with increased odds of proximal colon cancer. The report that age had a greater effect on proximal than distal colon cancer risk mirrors our findings of increased susceptibility to proximal adenoma recurrence with increasing age.

The use of NSAIDs has been shown to be inversely associated with the risk of adenoma recurrence in randomized control trials [19-21]. However, these studies did not evaluate the possibility of a differential protective effect by colon subsite. A reduction in colorectal cancer incidence has also been demonstrated with NSAIDs in cohort studies $[22,23]$. Among participants in the Nurses' Health Study, Chan et al. [22] reported a reduced risk of incident distal $(\mathrm{RRR}=0.64,95 \%$ CI 0.51 to 0.81 ) and proximal ( $\mathrm{RRR}=0.77,95 \%$ CI $0.62-0.94$ ) colon cancer among regular users ( 2 or more standard $325 \mathrm{mg}$ aspirin tablets per week). In a population-based retrospective cohort study, Smalley et al. [23] reported a reduced risk of colon cancer among recent users of NSAIDs with more than 12 months of cumulative use $(\mathrm{RRR}=0.77,95 \%$ CI $0.55-1.08$ for distal and $\mathrm{RRR}=0.48$, 95\% CI $0.34-0.68$ for proximal cancer). In our study, use of NSAIDs (at least once a month) was associated with approximately $50 \%$ decreased risk of advanced adeno$\mathrm{ma}$ in both the proximal and distal colon. Cardiac side effects observed in chemoprevention trials of cyclooxygenase-2 inhibitors [19-21] have precluded their recommendation as a chemoprevention strategy [24], and bleeding risk limits nonselective NSAIDs use. Developing chemopreventive agents with an acceptable riskbenefit ratio remains a goal.

There are many strengths of our study. Although, our study end point was not prespecified as part of the original PPT, the trial's comprehensive information on adenoma location provided an opportunity to compare distal and proximal adenoma recurrence. PPT was a large randomized controlled trial with participants recruited from geographically dispersed areas, informa- 
tion on candidate risk factors was prospectively gathered, all patients had planned colonoscopic assessment for recurrence after an adequate follow-up period, and dedicated trial pathologists with expertise in gastrointestinal tumors examined the adenomas, thereby ensuring consistency. However, our study has limitations. The participants in the PPT were self-selected and may be healthier than comparable members of the general population. Also, we could not assess the effect of serrated polyps, flat, and depressed lesions in our study because they were not widely discussed at the time the trial was conducted.

In conclusion, no modifiable risk factor for adenoma recurrence affect proximal versus distal adenoma recurrence differently to offer clinically useful guide for cancer prevention in the proximal colon. Further studies geared towards identifying individuals at a higher risk of metachronous proximal colon neoplasia are needed.

\section{Disclosure Statement}

Funding was from the National Cancer Institute. No author has any financial interests that may be relevant to the submitted work. An abstract from this study was presented as an oral presentation during Digestive Diseases Week in Chicago in 2009.

Dr. Laiyemo is supported by the National Cancer Institute's new faculty recruitment supplement to the Comprehensive Minority Institution/Cancer Center Partnership between Howard University Cancer Center and Sidney Kimmel Comprehensive Cancer Center of Johns Hopkins University (5U54CA091431-09 S1).

Dr. Doubeni is supported by a mentored career development award (5K01CA127118-03) from the National Cancer Institute.

\section{References}

$>1$ Doubeni C, Laiyemo AO, Reed G, et al: Socioeconomic and racial patterns of colorectal cancer screening among Medicare enrollees 2000-2005. Cancer Epidemiol Biomarkers Prev 2009;18:2170-2175.

$>2$ Subramanian S, Amonkar MM, Hunt TL: Use of colonoscopy for colorectal cancer screening: evidence from the 2000 National Health Interview Survey. Cancer Epidemiol Biomarkers Prev 2005;14:409-416.

$>3$ Singh H, Turner D, Xue L, Targownik LE, Bernstein CN: Risk of developing colorectal cancer following a negative colonoscopy examination: evidence for a 10-year interval between colonoscopies. JAMA 2006;295:23662373.

4 Lakoff J, Paszat LF, Saskin R, Rabeneck L: Risk of developing proximal versus distal colorectal cancer after a negative colonoscopy: a population-based study. Clin Gastroenterol Hepatol 2008;6:1117-1121.

$\checkmark 5$ Baxter NN, Goldwasser MA, Paszat LF, Saskin R, Urbach DR, Rabeneck L: Association of colonoscopy and death from colorectal cancer. Ann Intern Med 2009;150:1-8.

-6 Singh H, Nugent Z, Demers AA, Kliewer EV, Mahmud SM, Bernstein CN: The reduction in colorectal cancer mortality after colonoscopy varies by site of the cancer. Gastroenterology 2010;139:1128-1137.

7 Brenner H, Chang-Claude J, Seiler CM, Rickert A, Hoffmeister M: Protection from colorectal cancer after colonoscopy: a populationbased, case-control study. Ann Intern Med 2011;154:22-30.

$>8$ Rex DK, Eid E: Considerations regarding the present and future roles of colonoscopy in colorectal cancer prevention. Clin Gastroenterol Hepatol 2008;6:506-514.
$>9$ Deng G, Kakar S, Tanaka H, et al: Proximal and distal colorectal cancers show distinct gene-specific methylation profiles and clinical and molecular characteristics. Eur J Cancer 2008;44:1290-1301.

10 Ferracin M, Gafà R, Miotto E, et al: The methylator phenotype in microsatellite stable colorectal cancers is characterized by a distinct gene expression profile. J Pathol 2008;214:594-602.

$\checkmark 11$ Schatzkin A, Lanza E, Freedman LS, et al: The polyp prevention trial I: rationale, design, recruitment, and baseline participant characteristics. Cancer Epidemiol Biomarkers Prev 1996;5:375-383.

$>12$ Lanza E, Schatzkin A, Ballard-Barbash R, et al: The polyp prevention trial II: dietary intervention program and participant baseline dietary characteristics. Cancer Epidemiol Biomarkers Prev 1996;5:385-392. Erratum in: Cancer Epidemiol Biomarkers Prev 1996;5: 584.

13 Schatzkin A, Lanza E, Corle D, et al: Lack of effect of a low-fat, high-fiber diet on the recurrence of colorectal adenomas. Polyp Prevention Trial Study Group. N Engl J Med 2000; 342:1149-1155.

14 Laiyemo AO, Murphy G, Albert PS, et al: Postpolypectomy surveillance guidelines: predictive accuracy for advanced adenoma at 4 years. Ann Intern Med 2008;148:419-426.

15 Laiyemo AO, Doubeni C, Sanderson AK, et al: Likelihood of missed and recurrent adenomas in the proximal versus the distal colon. Gastrointest Endosc 2011;74:253-261.
16 Jacobs ET, Ahnen DJ, Ashbeck EL, et al: Association between body mass index and colorectal neoplasia at follow-up colonoscopy: a pooling study. Am J Epidemiol 2009;169:657-666.

17 Nelson RL, Dollear T, Freels S, Persky V: The relation of age, race, and gender to the subsite location of colorectal carcinoma. Cancer 1997; 80:193-197.

18 Gonzalez EC, Roetzheim RG, Ferrante JM, Campbell R: Predictors of proximal vs. distal colorectal cancers. Dis Colon Rectum 2001; 44:251-258.

19 Baron JA, Sandler RS, Bresalier RS, et al: A randomized trial of rofecoxib for the chemoprevention of colorectal adenomas. Gastroenterology 2006;131:1674-1682.

20 Bertagnolli MM, Eagle CJ, Zauber AG, et al: Celecoxib for the prevention of sporadic colorectal adenomas. N Engl J Med 2006;355: 873-884.

-21 Arber N, Eagle CJ, Spicak J, et al: Celecoxib for the prevention of colorectal adenomatous polyps. N Engl J Med 2006;355:885-895.

22 Chan AT, Giovannucci EL, Meyerhardt JA, Schernhammer ES, Curhan GC, Fuchs CS: Long-term use of aspirin and nonsteroidal anti-inflammatory drugs and risk of colorectal cancer. JAMA 2005;294:914-923.

-23 Smalley W, Ray WA, Daugherty J, Griffin MR: Use of nonsteroidal anti-inflammatory drugs and incidence of colorectal cancer: a population-based study. Arch Intern Med 1999;159:161-166.

24 Rostom A, Dubé C, Lewin G, et al: Nonsteroidal anti-inflammatory drugs and cyclooxygenase-2 inhibitors for primary prevention of colorectal cancer: a systematic review prepared for the US. Preventive Services Task Force. Ann Intern Med 2007;146:376-389. 